Copyright (C 2014 IEEE. Personal use of this material is permitted. Permission from IEEE must be obtained for all other uses, in any current or future media, including reprinting/republishing this material for advertising or promotional purposes, creating new collective works, for resale or redistribution to servers or lists, or reuse of any copyrighted component of this work in other works. 


\title{
Improving the Learning Experience of Power System Protection Students using Computer-based Simulations and Practical Experiments
}

\author{
Farhad Shahnia, Moayed Moghbel and Hadi Hosseinian Yengejeh \\ Electrical and Computer Engineering Department \\ Curtin University \\ Perth, Australia \\ farhad.shahnia@curtin.edua.au
}

\begin{abstract}
This paper presents a survey on the activities carried out to improve the learning experience of electrical engineering undergraduate students in power system protection unit in Curtin University, Australia. The unit was conducted initially based on lectures and tutorials where only two sessions on computer simulation and one session of laboratory demonstration were conducted. In academic year of 2013, to improve the learning experience of students, several computer-based simulations and laboratory experiments were prepared. The students are introduced with two power system analysis software, namely ETAP and PSCAD/EMTDC which are used to demonstrate the overcurrent relays performance and their coordination as well as the time transient analysis of different faults in an electric network where some protection relays are applied. A practical setup composed of LabVolt electrical modules and SEL relays is used to simulate an electric network. Several tests are built up to simulate fault and protection layout for transformer and induction motor. Finally, a secondary injection test set is used to introduce the concepts of relay testing and commissioning.
\end{abstract}

Index Terms-Power system protection, relay, education, student satisfaction

\section{INTRODUCTION}

Power System Protection (PSP) unit is offered as an individual unit for undergraduate or postgraduate students in few universities around the world. The main perquisite for this unit is the knowledge on power system analysis (mainly the load flow and short-circuit fault calculations), and its main objective is introducing different protection schemes (e.g. overcurrent, directional, distance, differential, thermal, earthfault, etc.), different relay types, (i.e. electromechanical, numerical and micro-processor-based), relay settings calculations and coordination of the relays in the power systems. IEEE Power System Relaying Committee (PSRC) has recommended in [1] that this unit should compose of standard lectures, laboratory sessions, software sessions and assignments. Among all these learning activities, this paper focuses on the laboratory and software sessions.

Laboratory exercises play a vital role in improving the learning experience of the students and are very useful for both educational and research purposes. The students obtain a lot of experience when working with physical systems in the laboratories. This helps them to combine the theories taught within the lectures on designing the proper settings for a physical device as well as to visualize the operation of the protection relays.

The rest of the paper is as follows: Section II discusses the different possibilities for PSP laboratories. A literature survey is carried out mainly focusing on the papers and reports published by the academics involved in PSP units around the world in developing PSP laboratories in their universities. The rest of the paper highlights the steps considered for improving the learning experience of the PSP students in Curtin University, Australia through the developed computer-based and experimental sessions. These activities are reported in Sections III-V. Section VI briefly demonstrates the feedback from the students on their total satisfaction from the discussed activities.

\section{DIFFERENT POSSIBILITIES FOR PSP LABARATORIES}

The main objective of the PSP laboratory is to provide students with practical and hands-on experience to apply the concepts and theories they learn in the lectures to standard industrial protection relays.

The main difficulty in developing a PSP lab in universities is the cost. Unfortunately, the protection relays are very expensive and each might cost around a few thousand dollars, depending on their features. Hence, developing software simulation-based PSP laboratories is the main option to overcome the lack of financial support. As an example, references [2-4] have discussed the software-based PSP laboratories, developed by the academics during 1989 to 1996.

Through the extensive use of Internet, the development of remote laboratories started in mid 1990s [5]. Among many educational courses, remote access PSP laboratories seem very appealing mainly due to cost reasons. The remote laboratories are more flexible from accessibility point of view. The students can connect to the computers located within a laboratory using internet and provided usernames at almost any time and re-run the activities as many times as they need [6]. Due to the internet-based platform, the students at almost all over the country can utilize the laboratory facilities in a university after proper arrangements and agreements are carried out among the universities. Since the protection relays can be tested remotely [7], a few remote PSP laboratories have been developed around the world such as the ones in University of 
Adelaide, Australia [8], Technical University of Catalonia, Spain [9] and Polytechnic Institute of Setubal, Portugal [10]. Although for some laboratories, the learning experience gained by the students is educationally equivalent to that obtained in traditional laboratory activities, presence of the students in the PSP lab and carrying out the experiments along with the relevant discussions among the students as well as between the students and the laboratory supervisors are highly important to improve the learning experience of the students [11].

References [12-13] have discussed the steps the academics in the American University of Tennessee at Chattanooga and Drexel University at Philadelphia have taken in developing an industrial PSP laboratory by the educational/industrial financial supports and using the micro-processor-based relays from Schweitzer Engineering Laboratories (SEL). Ref [14] demonstrates the performance of a scaled down laboratory experiment by a single computer implementing an Overcurrent (OC) protection strategy while [15] introduces a Real Time Digital Simulator (RTDS)-based relay testing facility.

Among the available literature on development of PSP laboratories, [16] represents a real PSP laboratory built in B.V.M. Engineering College, India based on an educational fund which had resulted in purchasing 107 relays. The same authors have also presented a developed distance protection example based on their PSP facilities in [17].

Reference [18] represents a small scale PSP laboratory developed based on SEL relays in Portland State University, USA. Due to the utilization of the actual relays in the labs introduced in $[16,18]$, the students are expected to be familiar with the hands-on experiences in PSP and directly be prepared for entry-level engineering positions in industry. Such a practical experience is highly important nowadays that the number of the experienced power engineers in industry is not sufficient.

The lack of funds prevent majority of the universities to build a real PSP laboratory. Hence, educational-purpose built small scale power simulators are of high interest for the universities. Among them, LabVolt [19], Terco [20] and Edibon [21] have the most well-known educationally-built protection working stations which provide the possibility of running protection-related experiments in the laboratories by the students. However, each working station from these manufacturers costs about a few ten thousand dollars.

\section{COMPUTER-BASED SOFTWARE SimULATIONS}

A list of about 42 dedicated software for power system analysis is reported in [22] where about $75 \%$ of the software are commercially available in the market. Most of these software have educational or student versions which are available free or at a very low price for universities and students. A few of these software contain specifically designed protection modules. Hence, such software can be utilized by the students to understand the concepts of different protection schemes. The well-known software to be used by PSP students are ETAP [24], DIgSILENT Power Factory [25], CYME [26-27], IPSA [28], PSCAD [29] and PSS SINCAL [30].
To balance the students experience on software simulations in addition to the practical experiments, a set of softwarebased simulations are developed and utilized in Curtin University, Australia. In the academic year of 2013, a series of ETAP-based videos were prepared. The videos are captured and edited by Echo360 software [32] and then made accessible for the PSP unit students through the university Blackboard system [33]. The students enrolled in the unit can access the recorded material 24/7 from any computer/laptop or tablet online or after being downloaded. The recorded videos contain:

- The basic steps in being familiar with the software, its environment, features, modes, etc.,

- The software library and different components available,

- Drawing a single-line diagram network in the software,

- Defining the ratings and numerical specifications for all the components in the single-line diagram,

- Load flow analysis, building different load flow projects, retrieving load flow analysis reports in different formats, adjusting the ratings of the conductors, busbars, Circuit Breakers (CB), Current Transformers (CT) and Potential Transformers (PT) based on the load flow analysis,

- Short-circuit analysis, building different short-circuit projects, understanding the difference of the available standards on short-circuit calculations, retrieving shortcircuit analysis reports in different formats, adjusting the circuit breaker ratings based on the short-circuit analysis,

- Design of proper settings for the OC relays and interlinking them with the CTs and $\mathrm{CBs}$, selecting proper options from the available models in ETAP library, defining Time Multiplier Settings and Pickup levels for the relays,

- Protection coordination for the OC relays, adjusting the relays operation time to provide proper backup system for each relay, plotting the Time Curve Characteristics (TCC) for the relays in one bay,

- Adjusting the differential protection for the transformers in the single-line diagram.

Fig. 1(a) shows one sample project used by students to be designed and arranged using the load flow, short-circuit, protection coordination capabilities of ETAP. Fig. 1(b) shows the coordination result for a fault at bus-3 of the system. The operation time of the relays and the CBs are listed in Table 1.

It is to be noted that unfortunately ETAP has no distance protection capability in its current version (v.12). To carry out experiments in distance protection, the DIgSILENT PowerFactory and Neplan software are suggested.

The simulation above helps the students to understand and visualize the short-circuit studies and protection issues from a steady-state point of view. To visualize the time-domain operation, PSCAD-based simulations are developed and will be introduced in the academic year 2014 for the PSP students in Curtin University. A set of recorded tutorials are developed on PSCAD and will be made available for the students enrolled in the unit through Blackboard system. These simulations demonstrate the differential protection of a transformer, distance protection of a transmission network as well as OC protection and coordination of a distribution feeder. As an example, a snapshot of a feeder used for OC protection 
and coordination is shown in Fig. 2(a). After proper design of the main and backup OC protection for a fault at a given bus, a fault is applied at that bus and the coordination of the relays is observed in time domain.

To integrate the new subjects of electrical engineering such as Distributed Generators (DG), two sample case studies, one in ETAP and one in PSCAD have been developed. These two case studies demonstrate a network with proper coordination of the OC relays which gets affected after the presence of the DGs as a function of their ratings and installation at different buses. As an example, Fig. 2(b) shows a power system with 3 DG units in at different buses, modelled in PSCAD.

Fig. 2(c) shows a sample result for the system of Fig. 2(a), for a three-phase ground fault at $t=1 \mathrm{~s}$ at bus- 4 , in which the main OC protection operates at $t=1.3 \mathrm{~s}$ while the backups operate with a desired $0.3 \mathrm{~s}$ time differences.

Fig. 2(d) shows a table based on the summarized data of OC protection operation time for a fault at a given point considering different generation levels of the DGs. The red sections in the table demonstrate that a coordination mismatch is been detected due to the presence of DGs in the network. This example can easily demonstrate the students that even if a proper coordination is carried out for a system, the addition of DGs adversely affects the designed OC protection scheme.

It is to be noted that the main educational procedure for the software-based simulations is utilizing the recorded tutorials; hence, the students can attend more experimental laboratory activities throughout the semester without increasing the official contact hours of the students for the unit.



(a)



(b)
Fig. 1. (a) Sample project to be modelled and analyzed by PSP students in ETAP to provide a desired OC protection system and coordination, (b) the coordination result.
Table 1. The time sequence of $\mathrm{OC}$ relays and $\mathrm{CBs}$ operation.



Fig. 2. (a) Sample project to be modelled and analyzed by PSP students in PSCAD to provide a desired OC protection system and coordination, (b) the system considering the presence of DG units on OC coordination scheme, (c) sample results for the main and backup OC relays after a fault in system of (a), (d) summarized data from OC protection operation time for a fault, considering different generations for a DG in the system of Fig. 2(b).

\section{EXPERIMENTS USING POWER SYSTEM SIMULATOR}

The developed experiments are based on the LabVolt power system simulator. In the academic year 2013, only the educational relays available in the LabVolt working station were utilized by the students. However, from academic year 2014, the industrial SEL relays will be replaced instead of the educational relays of LabVolt to provide the students with better hands on experience. The relays are configured properly and the students will only be requested to apply the numerical settings, they have calculated in the pre-laboratory activities, to the relays. Fig. 3 shows the PSP laboratory, developed in Curtin University.

The designed laboratory experiments are to help the students to visualize and understand:

- Differential Protection of Transformer

- Restricted Earth Fault Protection of Transformer

- Phase Unbalance and Under/Over Voltage Protection of Induction Motor

- Overcurrent Protection of Induction Motor

The developed experiments are discussed briefly below:

\section{A.Differential Protection of Transformer}

Differential protection is based on the fact that under normal conditions the currents in the secondary of the two current transformers (CT) located at the primary and secondary of the transformer are equal. Therefore, the difference of these two currents, passing through the differential protection 
is zero. During a fault within the differential protection zone, this current difference is non-zero and the protection relay trips.

Fig. 4 shows the schematic diagram of the utilized differential protection for a transformer. This protection is applied for a LabVolt fault-able three-phase transformer. A phase-tophase and phase-to-ground faults are applied in the transformer windings. An overcurrent educational relay module is utilized to trip the circuit once the current passing through it is higher than a pre-defined value. This value, which is very close to zero, is defined such that the initial energizing of the transformer and its inrush current does not trip the device.

The experiment is repeated for a fault outside the differential protection zone and it is demonstrated that the differential protection does not trip for the faults outside the zone.

\section{B. Restricted Earth Fault Protection of Transformer}

Restricted Earth Fault (REF) protection of transformer windings is a complementary protection for transformer differential protection. Fig. 5 shows the schematic diagram of the utilized REF protection for a transformer. This protection is applied for a LabVolt fault-able three-phase transformer with a star-grounded connection. A phase-to-ground fault is applied in the transformer secondary windings. A total of 4 CTs are used- three to monitor the three-phase secondary line currents and one to monitor the current of the transformer neutral. The secondary of all CTs are connected in parallel and then to the protective relay. A single-phase overcurrent protective relay is used.

In normal condition, the vector sum of the currents at the secondary of the line CTs after being multiplied by the CTs ratio is equal to the secondary current of the CT located in the transformer neutral, after being multiplied by its ratio. During a fault, these two values are not equal and their difference passes through the OC relay. Hence, the fault is detected by the utilized REF protection scheme.

The experiment is repeated for a fault outside the REF protection zone and it is demonstrated that the REF protection does not trip for the faults outside the zone.

\section{Phase Unbalance and Under/Over Voltage Protection of Induction Motor}

Fig. 6 shows the schematic diagram of the utilized unbalance and undervoltage protection of an induction motor. This protection is applied for a LabVolt squirrel cage three-phase induction motor. An educational unbalance relay and an educational under/over voltage relay are used.

First, voltage sag is applied to the motor using the adjustable voltage supply. Once, the voltage drops below the predefined limit of the undervoltage relay, the relay picks up the non-standard voltage and trips the circuit after the pre-defined time period. Similarly, voltage rise is applied through an external autotransformer and when the voltage rises above the pre-defined limit of the overvoltage relay, the relay picks up the non-standard voltage and trips the circuit after the desired time period.

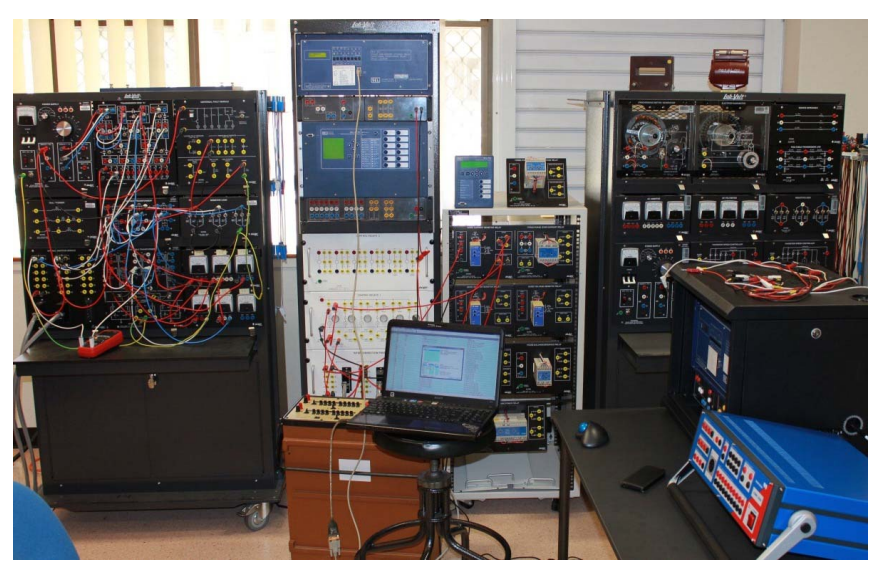

Fig. 3. PSP laboratory in Curtin University.



Fig. 4. Schematic diagram of the utilized differential protection demonstration.



Fig. 5. Schematic diagram of the utilized REF protection demonstration.

To apply voltage unbalance for the motor, one of the threephase power supply connections is disconnected. In this case, the unbalance relay picks up the unbalance as soon as it exceeds the pre-defined limit of the relay. Then, the relay trips the circuit after the pre-defined time period. It is to be noted that due to a phase loss, both the undervoltage relay and the unbalance relay pick up the fault. However, they trip at different time periods, based on the pre-defined time periods of each of them.

The last experiment for this setup is to apply the threephase voltage in a reverse sequence. For this, any arbitrary 
two phases of the three-phase power supply output are interchanged. Hence, the unbalance relay picks up the reverse rotation of the motor from the reverse sequences of the voltage and trips the circuit after the pre-defined time period.

\section{Overcurrent Protection of Induction Motor}

Fig. 7 shows the schematic diagram of the utilized OC protection of an induction motor. This protection is applied for a LabVolt squirrel cage three-phase induction motor. An educational three-phase OC relay is used.

The OC relay picks up whenever the monitored current exceeds the pre-defined pick-up limit of the relay. Then, it trips the circuit after a pre-defined time period. The time setting of the relay is chosen such that the circuit does not trip by the OC relay at the initial starting time of the motor.

\section{STAND-AlONE RELAY TEST EXPERIMENTS}

Two different stand-alone tests of the relays are implemented for PSP experiments, as discussed below:

In the first experiment, a secondary injection set of Omicron CMC356 [34] is used to test one SEL321 (OC and distance) protection relay and one SEL487 (transformer differential) protection relay. The two relays have been already configured and some settings are applied for them. This test system is as shown in Fig. 8. The main objective of this experiment is introducing the fundamentals of relay testing procedure. It is to be noted that since Omicron CMC356 is an expensive device, the injection sets of Ponovo [35] may be a more affordable option for the PSP laboratories of the universities.

The second stand-alone test experiment is based on testing a relay, with pre-defined configurations and settings but with a COMTRADE file, saved from PSCAD simulations. In this experiment, a power system is simulated in PSCAD and the current and voltage time-domain waveforms are stored as a COMTRADE file. This file is later imported by OMICRON software and the same currents and voltages are generated by the injection set and applied to the relay. This test can demonstrate that if the settings defined by the students for a relay operates successfully for a simulated fault at the power system. This test will be conducted by the PSP students of Curtin University in academic year 2014.

\section{STUDENTS ASSESSMENT}

In addition to the expected improvement in the students learning experience, their laboratory activities will be assessed. This assessment is based on monitoring and evaluating the students' success in meeting the expected learning outcomes from these laboratory experiments.

The assessment of PSP laboratory consists of $20 \%$ of the final mark for this unit. $10 \%$ of the mark is based on the report regarding the simulation-based activities and the other $10 \%$ is based on report they hand in regarding the practical experiments. To minimize the workload of the students, only 2 lab reports (one simulation-based and one practical-based) are required at the end of the semester.

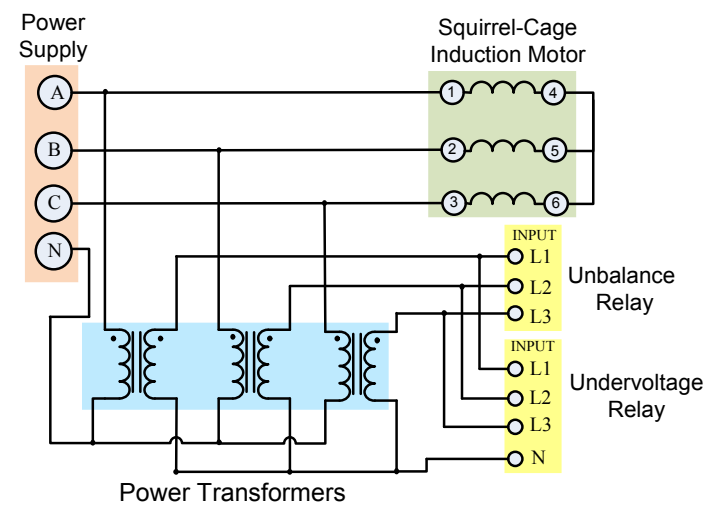

Fig. 6. Schematic diagram of the utilized unbalance and under/over voltage protection demonstration.

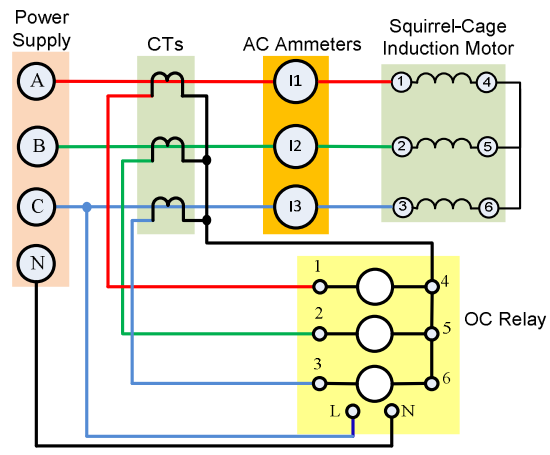

Fig. 7. Schematic diagram of the utilized overcurrent protection demonstration.
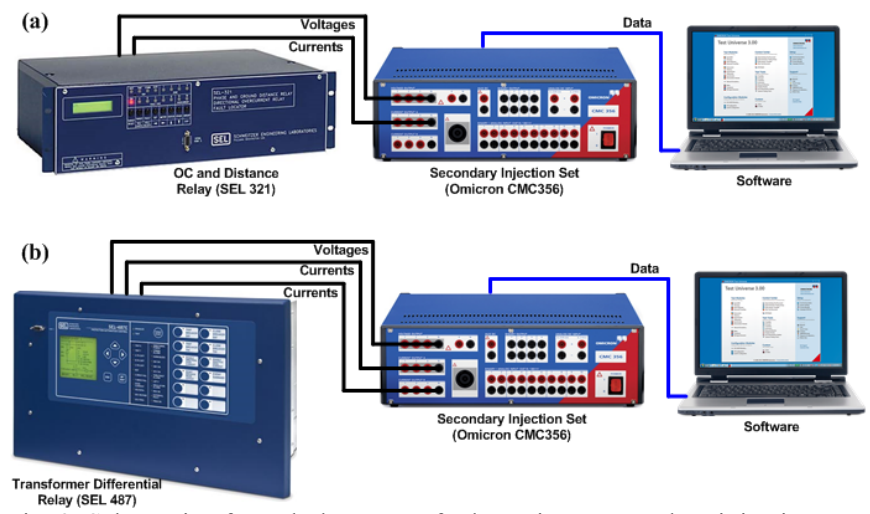

Fig. 8. Schematic of stand-alone test of relay using a secondary injection set.

In the simulation-based lab report, the students need to model, design and analyze a given network in ETAP and PSCAD. They have to calculate the proper settings for the components, run some load flow and short-circuit analysis tests and then summarize the results in table or figure formats. Then, it is requested that they provide a short discussion on the main understandings and outcomes of the project.

The practical-based lab report is a survey of all the practical experiments which they have carried out through the semester. It is expected that the students briefly explain the experiments, the mechanism of different protection schemes, procedure each protection scheme is applied for the power system simulator, answer the questions throughout the lab manuals and also highlight the main new issues they have visualized in those activities. 
The students submit their lab reports in pdf format online (through the BB system) in different groups. A detailed rubric is prepared where the lab supervisors need to consider when marking the lab reports. To provide a better feedback for the students, the lab supervisors provide comments on each lab report using the Adobe Acrobat Commenting tool [36]. This is a very versatile tool in providing feedback to students as the lab supervisors can easily highlight the mistakes and correct calculations/assumptions throughout the text. In addition, the lab supervisors add a voice comment on each lab report which gives the main feedback to the students on their lab report. To provide a guide for the lab supervisors on how to access the online lab reports submitted by students, mark it and return it back to the students, a short video was created and recorded [37].

\section{STUDENTS FEEDBACK}

Due to the improved learning experiences in PSP unit, there has been a high number of interest by the undergraduate and Master by coursework students, with the major of electrical power engineering, to carry out their Final Year Projects (FYP) on PSP-related subjects. Hence, about 10-15\% of the students graduating in 2013 and 2014 carried out PSPrelated FYPs. Fig. 9 shows the PSP-related FYPs, by undergraduate and master by coursework students, in Curtin University during academic year 2008-2014.



Fig. 9. Number of FYPs by undergraduate and master by coursework students in Curtin university.

\section{CONCLUSION}

A survey on the simulation-based and practical-based activities carried out to improve the learning experience of electrical engineering undergraduate students in PSP unit in Curtin University, Australia is presented in this paper. The students become familiar with the network modelling, load flow, short circuit analysis and $\mathrm{OC}$ protection and coordination in ETAP. In addition, they visualize the time domain fault results with $\mathrm{OC}$, distance and differential protections in PSCAD/EMTDC. The OC and REF protection for the transformer as well as the OC, Under/Over voltage and phase unbalance protections for the induction motor are demonstrated in practical experiments, by the help of LabVolt electrical modules. An Omicron secondary injection test set is also used to test the configurations and settings of SEL321 and SEL487 relays. By the help of the developed experiments, the conversations during the practical sessions and the feedback provided to the students, the students became more interesting in PSP and were encouraged in taking more FYPs in this area.

\section{REFERENCES}

[1] S. Brahma, J. De La Ree, J. Gers, et al. "The education and training of future protection engineers: challenges, opportunities, and solutions," IEEE Trans. on Power Delivery, Vol. 24, Issue 2, pp. 538-544, 2009.

[2]M.A. Redfern, R.K. Aggarwal, and G.C. Massey, "Interactive power system simulation for the laboratory evaluation of power system protection relays," in Proc. of the Int. Conf. on Development of Power System Protection, pp. 215-219, 1989.

[3] T.S. Sidhu and M.S. Sachdev, "Laboratory setup for teaching and research in computer-based power system protection," in Proc. Int. Conf. Energy Manage. Power Del., Vol. 2, pp. 474-479, 1995.

[4] M.S. Sachdev and T.S. Sidhu, "Laboratory for research and teaching of microprocessor-based power system protection," IEEE Trans. on Power Systems, Vol. 11, No. 2, pp. 613-619, May 1996.

[5] J. Trevelyan, "Lessons learned from 10 years experience with remote laboratories," in Proc. of the Int. Conf. on Engineering Education and Research, 2004.

[6] A. Maiti and B. Tripathy, "Remote Laboratories: Design of Experiments and Their Web Implementation," Educational Technology and Society, Vol. 16, No. 3, pp. 220-233, 2013.

[7] M. Musaruddin, M. Zaporoshenko and R. Zivanovic, "Remote protective relay testing," in Proc. of the $18^{\text {th }}$ Australasian Universities Power Engineering Conf. (AUPEC), 2008.

[8] R. Zivanovic, "Setting and testing SEL710 via remote relay test system," Collaborative Power Engineering Centers Of Excellence, Australian Power Institute, 2010.

[9] R.P. Martinez, R.V. Robles, P.L. Gallego, et al. "Protection system remote laboratory," in Proc. of the $11^{\text {th }}$ Int. Conf. on Electrical Power Quality and Utilization (EPQU), pp. 1-6, 2011.

[10] V.F. Pires, L.S. Martins, T.G. Amaral, et al. "Distance-Learning PowerSystem Protection Based on Testing Protective Relays," IEEE Trans. on Industrial Electronics, Vol. 55, Issue 6, pp. 2433-2438, 2008.

[11] A.A. Kist, "Barriers to Adopting Remote Access Laboratory Learning Activities," in Proc. of the Annual Conf. of Australasian Association for Engineering Education (AAEE), 2012.

[12] A.H. Eltom, and R. Harnchotipun, "Microprocessor-based relay laboratory with industry support," in Proc. of IEEE Power Engineering Society Summer Meeting, Vol. 3, pp. 1457-1461, 2002.

[13] S.P. Carullo and C.O. Nwankpa, "Interconnected power systems laboratory: a computer automated instructional facility for power system experiments," IEEE Trans. on Power Systems, Vol. 17, Issue 2, pp. 215$222,2002$.

[14] S.M.L. Kabir, "Computer operated coordinated over-current protection scheme," in Proc. of the Universities Power Engineering Conf. (UPEC), pp. 79-83, 2000.

[15] P.G. McLaren, R. Kuffel, R. Wierckx, et al. "A real time digital simulator for testing relays," IEEE Trans. on Power Delivery, Vol. 7, No. 1, pp. 207-213, 1992.

[16] B.A. Oza and S.M. Brahma, "Development of power system protection laboratory through senior design projects," IEEE Trans. on Power Systems, Vol. 20, Issue 2, pp. 532-537, 2005.

[17] R. Mehta, B. Oza, N.K.C. Nair and M. Kumar, "Simulation of numerical distance protection through senior design project," in Proc. of IEEE Int. Conf. on Power System Technology (POWERCON), pp. 1-6, 2012.

[18] J. Ferris and R.B. Bass, "A Power Systems Protection Teaching Laboratory for Undergraduate and Graduate Power Engineering Education," $120^{\text {th }}$ American Society for Engineering Education (ASEE) Annual Conf. and Exp., pp. 1-8, 2013.

[19] $0.2 \mathrm{~kW}$ Protective Relaying Training System, Model 8007, https://www.labvolt.com/downloads/dsa8007.pdf

[20] Transmission Line, Transformer \& Protection Laboratory, http://www.tercosweden.com/wpcontent/uploads/2009/06/transmissions_line _transformer_protective_relays.pdf

[21] ERP-UB. Protection Relays Test Unit http://www.edibon.com/products/catalogues/pt/units/energy/relaysunits/ERP.pdf

[22] Power Systems Analysis Software, Wikipedia, http://www.openelectrical.org/wiki/index.php?title=Power Systems Analysis So ftware

[23] Star-Protection and Device Coordination Catalogue, ETAP, http://etap.com/downloads/brochures/star_artts.pdf

[24] DIgSILENT PowerFactory Power System Analysis Software Catalogue, http://www.albanah.org/ss/attachment.php?attachmentid=352 
[25] Selectivity Analysis Catalogue, NEPLAN,

http://www.neplan.ch/html/e/pdf_e/NEPLAN_B05_SelectivityAnalysis_engl.pdf

[26] Distance Protection Catalogue, NEPLAN, http://www.neplan.ch/html/e/pdf_e/NEPLAN_B06_DistanceProtection_engl.pdf

[27] Protective Device Coordination with CYME and CYMDIST, CYME,

http://www.ipet-co.com/en/download/cymecymtcc/B1100-09076-EmbeddedCYMTCC.pdf

[28] Protection Grading, IPSA,

http://www.ipsa-power.com/software/ipsa-2-1/protection-grading

[29] Applications of PSCAD/EMTDC, Manitoba HVDC Research Inc., http://www.ien.pw.edu.pl/install/PSCAD/PSCAD\%204.2.1 Professional\%20+\%2 0LiveWire $\% 202.3$ zakup $\% 20 z \% 20$ grantu-

2008/Install/PSCADV4/Help/HelpManuals/Application\%20Guide\%202007.pdf
[30] PSS SINCAL Platform 10.5 Release Information, Siemens, http://sincal.s3.amazonaws.com/10.5/ReleaseNotesEng.pdf?AWSAccessKeyId=05D315V4JJ99N5PASW02\&Expires $=1451606400$ \&Signature $=$ MymTUdooljbEJeSKxVbdacDTBAA $\% 3 \mathrm{~d}$

[31] Echo360 Active Learning Website, http://echo360.com/

[32] Blackboard Inc. Website, http://anz.blackboard.com/sites/international/globalmaster/

[33] Omicron CMC356: The universal relay test set and commissioning tool,https://www.omicron.at/fileadmin/user_upload/pdf/literature/CMC -356-Brochure-ENU.pdf

[34] Ponovo Universal test system L336i, http://www.relaytest.com/userfiles/file/Catalogs/L336i_Brochure.pdf

[35] Adobe Acrobat Commenting Tool http://tv.adobe.com/watch/acrobat-tips-and-tricks/using-familiar-commentingtools/

[36] Guide on online marking and commenting student lab reports through Blackboard system, http://screencast.com/t/CH87wLLp 